\title{
Mobile Banking Usability Evaluation Among Deaf: A Review on Financial Technology and Digital Economy Prospects
}

\author{
https://doi.org/10.3991/ijim.v13i11.11512 \\ Vikniswari Vija Kumaran ${ }^{(凶)}$ \\ Universiti Tunku Abdul Rahman, Negeri Perak, Malaysia \\ vijakumaran22@gmail.com \\ Shelena Soosay Nathan \\ Universiti Tun Hussein Onn Malaysia, Johor, Malaysia \\ Azham Hussain, Nor Laily Hashim \\ Universiti Utara Malaysia, Malaysia, Kedah, Malaysia
}

\begin{abstract}
This study is aimed to explore the dimensions for appropriate deaf people usability evaluation model for M-banking application in order to enhancetheir satisfaction. Through the systematic literature review (SLR) conducted, four dimensions (efficiency, effectiveness, satisfaction and accessibility) have been identified to be appropriate to suit the need of m-banking application usability evaluation especially for the deaf people. Furthermore, innovation and technologies through digital economy are practical and aptly accessible to allows persons who are deaf to fully participate in society, education, and business while also providing prospects for personal and professional advancement. Moreover, this study will be able to provide recommendation to the upper management of Malaysia Banks to concern on mobile services in order to enhance the deaf customers' satisfaction. Financial and economy implications together with future research suggestions are also discussed in this study.
\end{abstract}

Keywords-M-banking Usability, Financial Technology, Digital Economy, Deafness.

\section{Introduction}

Recently, banking relating to services begin via mobile appear on a large scale. Through this study, the researcher links banking service via mobile to effect on customer E-satisfaction especially for deaf people on their own without the need for assistance by the bank employee. The Importance of the of mobile banking service and the importance of converging on the service provided by the banks adopted, this study subject field use seven dimensions proportion that are very important to provide this service and they are: efficiency, effectiveness, satisfaction and accessibility. Digital economy shows the production, services, lifelong learning and innovation that are 
made possible by modern technology support in the context of market globalization and sustainable development.

Hearing loss Earshot expiration or deaf is an invisible health condition with important implications stipulation with important significance on the individual's quality of life. Deafness often remains invisible, especially in contexts context of constrained resource and poverty. High level of disability may reduce national economic growth, decreases productivity and increases healthcare costs. It can exact a high cost for both developed and developing countries development because it has a significant impact on the lives of those affected, and the economic system of the countries in which they live. Approximately $5.3 \%$ of the world's population suffers from disabling hearing loss; listening red ink; majority of individuals with disabling hearing loss live either in low or middle income countries. Countries with the lowest gross national income per capita have the highest numbers of children who are deaf. Deaf people deserve services because of their rights as people and because societies club ought to strive for humanistic values in attending to people's needs.

In general, the majority of the deaf depends on visual communication, that is, the Malaysian Sign Language (BahasaIsyarat Malaysia in Malay), and they have low proficiency in the Malay language, which is their second language (Ow, S.H. et al., 2007). Thus, there is less opportunity for them in socio-economic development of the country and they also have less access to information due to the communication gap between them and the hearing community. Developing technologies are practical and aptly accessible to allows persons who are deaf to fully participate in society, education, and business while also providing prospects for personal and professional advancement. There are only few studies have addressed the technology use of individuals someone who are deaf, none exist that focus on the needs, preferences, and accessibility of current Internet and mobile based technologies. Today many people around the world obtain information related to education, business, news, intelligence, and events via the Internet Cyberspace through computers and various mobile-based technologies. The Internet users worldwide have more than doubled since 2007, reaching 2.27 billion users worldwide in 2012 .

\section{$2 \quad$ Literature Review}

\subsection{M-banking usability evaluation}

M-banking usability evaluation has been overlooked despite the impact on the develper of mobile applications, usbaility practitioners and especially the deaf user and banking sector (Hussain, Abubakar, Hashim,2014). This leads towards various challenges towards usability issues of m-banking applications among deaf users. Literatures constantly focusing on general application evaluation rather forget the need of any application for disabled user as well such as the deaf user (Nathan et al., 2018; Yeratziotis \& P. Zaphiris, 2017; Nathan, Hussain \& Hashim, 2017). It is regrettable that issues concerning m-banking applications in terms of usable interface for deaf such as navigavtion, accesible features, trust, security, menu functions and presenta- 
tion are not adequately addressed. Studies such as Zhuo and Li (2010) mentioned on the dimenstions set that defined in evaluation of m-banking however, there is lesser descriptions on the usage of the usability dimensions in the evaluation process, thus making it quite difficult to apply the model for a specific application (Abubakar, Hashim \& Hussain, 2016; Nathan et al., 2016). Besides that, the findings revealed that the majority of the banks lack details on m-banking introduction on their website, whereby customers can only acquire the process of $\mathrm{m}$-banking after using the application. Sangar and Rastari (2015) proposed a model for increasing the usability of mbanking applications on smart phones with Android-based operating system focused on the development and implementation of m-banking applications using a set of usability dimensions. The usability dimensions presented in the study has no representation of metrics for each of the defined dimension. Therefore, the attempt to measure usability of m-banking applications with such model may be wasted and may not yield significant results. This indicates that the level of usability achievement is very limited and it depends on the experience of the evaluator or mobile application developer as metrics and guidelines for using the model were not provided.

There are many usability evaluation models introduced in the literature but most of them did not provide overall descriptions on how to select criteria or metrics to each corresponding usability dimension (Coursaris \& Kim, 2011; Baharuddin, et al., 2013). Besides that, importantly,none of the models have discussed usability from the perpective of deaf users. Moreover, most of the usability models are for general application thus, it be difficult to apply for a single mobile financial application due to complexity and clarification of the dimensions used for deaf users particularly. Besides, many of these models lack adequate descriptions for the selection of criteria and metrics that correspond to dimensions defined (Abubakar, 2016; Coursaris \& Kim, 2011). Generally, most of the studies above did not use founded usability evaluation models. with relevancy to m-banking application and deaf users.

\section{Financial Technology}

Financial technology (fintech) is more of the digitization trend helping to reduce costs and it will be very much the branch costs. The numbers of banks that offer Mobile banking application along with Web site access has keep increasing throughout the years. Common uses for mobile banking include retrieving account balances or recent transactions, transferring money between accounts, and receiving accountrelated alerts. Total users in quarter three recorded $146 \%$, more than $100 \%$ against the total population in Malaysia. The rapid growth, adoption of the digital technology, particularly in smartphone users and other handheld gadgets become the principal way for the great unwashed to start out online ( Murad et al., 2016). The Mobile revolution is currently changing many industries by improving networks of interaction and providing services to previously for sectors such as health care and banking. Recently, banks have radically converted from the traditional use of banking to branchless positions of banking. The latest adoption of using technology has helped banks applied science has helped depository financial institution to extend their customer client 
base, while electronic banking has proved to be the main advancement. Mobile banking categorized as the latest development in electronic bank services, whereas customer can do balance inquiry, credit transfer, and check chip account, SMS, Master of Science, payment transaction dealing and other businesses. From customers' perspective, the benefits of mobile banking service are convenience to perform banking transactions in anytime, anywhere and easy way. While in Malaysia, Central Bank has reported that there were 19.8 million internet banking subscribers and 7,279,000 mobile banking subscribers in December 2015. These figures show that percentage of penetration of mobile banking to reach $63.7 \%$ of the total population (Low et al., 2017).

\section{Digital Economy}

The banking industry in Malaysia is important because a strong banking industry support economic developments significantly through its efficient services. However, most of information through onlineapplications remains unreachable to individuals who are deaf (Harkins \& Bakke, 2003; NAD, 2012), which could ultimately lead to economic and social disparity. Indications on the survey, including prominent use of smartphones and social media such as Facebook, may indicate that the deaf community is more closely aligned to the general population. At the same time, the desire for captioning, and significant differences in results by demographics such as disability and household income, may indicate that there still exists a "digital divide." Groups with no access or unequal access to information and technologies are said to be "disadvantaged in the global economy" (Sey et al., 2013, p. 27). Use of technology and Web affect their success and fail to connect the persons socially (Rowland, Burgsthaler, Smith, \& Coombs, 2013). By solving the issues above, Malaysia will be overall transform from a production economy to a knowledge-based economy.

Thus, the aim of this study is toidentifydetailed dimension and measurement from literature study conducted for appropriate deaf people usability evaluation model for m-banking application that effect $\mathrm{m}$-banking services on enhancing deaf customers' and provide recommendation to the upper management of Malaysia Banks to concern on mobile services in order to enhance the deaf customers' satisfaction. This study will be able identify the development of technology in m-banking service that effect the deaf customer usability which had not previously addressed in the Malaysia Banking environment. Next section will discuss on the method used in identifying the dimensions and measurements followed with the discusion on the findings from the literature.

\section{$5 \quad$ Methodology}

In the development process of an appropriate model for usability evaluation, a systematic literature review (SLR) was used. SLR is an approach that mainly being used in repeating existing evidence on the treatment of any data which can be utilize in summarizing empirical evidence for further related studies (Kitchenham, 2004). This 
method is used in identifying the usability dimensions from various related literatures of human and mobile computer interaction respectively. As such, this provide an idea in generating appropriate dimensions for identifying usability issues for deaf people in the mean of m-banking application usage. To achieve the objective of the paper, studies from different human and mobile computer interaction articles and proceedings have been selected and analyzed accordingly. Combination of both primary and specific dimensions is the expected result to be obtained. To achieve this, the study applies on identifying only on the usability study area, evaluation method or design as well as papers that provides usability design and dimensions guidelines. All the relevant papers selected were carefully reviewed so as to gather quality information for creating the dimensions and measurements (Nathan et al., 2018; Abubakar et al., 2016). Table1 illustrates the selected journals and conference proceedings.

Table 1. Selected journals and conference proceedings for SLR

\begin{tabular}{|l|l|}
\hline \multicolumn{1}{|c|}{ Journals / Conferences } & \multicolumn{1}{c|}{ Publisher } \\
\hline Software Quality Journal & Springer Science \\
\hline $\begin{array}{l}\text { International Journal of Human Computer Interaction } \\
\text { (IJHCI) }\end{array}$ & Taylor and Francis \\
\hline Journal of Usability Studies & JUS \\
\hline $\begin{array}{l}\text { International Journal of Computer Science Education } \\
\text { (IJCSE) }\end{array}$ & $\begin{array}{l}\text { Association of Computer Machinery } \\
\text { (ACM) }\end{array}$ \\
\hline $\begin{array}{l}\text { International Journal of Mobile Human Computer } \\
\text { Interaction (IJMHCI) }\end{array}$ & IGI Global \\
\hline $\begin{array}{l}\text { International Conference on Human Computer Interaction } \\
\text { with Mobile Device and Services (CHCI) }\end{array}$ & ACM \\
\hline International Journal of Computer Studies (IJCSI) & Science Direct \\
\hline Journal of Deaf Studies & Gallaudet Publisher \\
\hline
\end{tabular}

Papers that are selected from the journals and proceedings will be categorized according to research type and knowledge area (Kitchenham, 2004). Papers that are grouped together will then read carefully and thoroughly to search the relevant dimensions that are based on the ISO 9241-11 (1994). Total of 431 journals and conference proceeding papers were downloaded and used for further reading to select the most relevant for the study shown in the Table 2 below. However, based on the quality and relevancy of the paper, only fifty two (52) papers were selected for review. Table 3 below indicates the journal or conference in general and specific, year of publication and number of papers downloaded:

Table 2. Total downloaded papers for SLR

\begin{tabular}{|l|l|l|l|l|l|l|l|l|l|l|l|l|}
\hline \multicolumn{1}{|c|}{ Category } & $\mathbf{0 6}$ & $\mathbf{6} \mathbf{0 7}$ & $\mathbf{6} \mathbf{0 8}$ & $\mathbf{6} \mathbf{0 9}$ & $\mathbf{6} \mathbf{1 0}$ & $\mathbf{'} \mathbf{1 1}$ & $\mathbf{'} \mathbf{1 2}$ & $\mathbf{'} \mathbf{1 3}$ & $\mathbf{'} \mathbf{1 4}$ & $\mathbf{'} \mathbf{1 5}$ & $\mathbf{'} \mathbf{1 6}$ & $\mathbf{1 7}$ \\
\hline Usability in general & 13 & 13 & 10 & 16 & 15 & 17 & 13 & 18 & 17 & 13 & 11 & 10 \\
\hline HI Usability & 14 & 15 & 17 & 21 & 16 & 18 & 15 & 19 & 16 & 15 & 18 & 8 \\
\hline Other related (HCI) & 3 & 5 & 4 & 4 & 8 & 6 & 7 & 7 & 8 & 9 & 8 & 4 \\
\hline Total & 30 & 33 & 31 & 41 & 39 & 41 & 35 & 44 & 41 & 37 & 37 & 22 \\
\hline
\end{tabular}


Table 3. Total selected paper

\begin{tabular}{|l|c|c|c|c|c|c|c|c|c|c|c|c|}
\hline \multicolumn{1}{|c|}{ Category } & $\mathbf{6 0 6}$ & $\mathbf{\prime} \mathbf{0 7}$ & $\mathbf{'} \mathbf{0 8}$ & $\mathbf{'} \mathbf{0 9}$ & $\mathbf{'} \mathbf{1 0}$ & $\mathbf{'} \mathbf{1 1}$ & $\mathbf{'} \mathbf{1 2}$ & $\mathbf{'} \mathbf{1 3}$ & $\mathbf{'} \mathbf{1 4}$ & $\mathbf{'} \mathbf{1 5}$ & $\mathbf{'} \mathbf{1 6}$ & $\mathbf{'} \mathbf{1 7}$ \\
\hline Usability in general & 5 & 1 & 1 & 2 & 2 & 1 & 6 & 2 & 1 & 2 & 1 & 1 \\
\hline HI Usability & 2 & 1 & 2 & 1 & 4 & 3 & 3 & 4 & 1 & 2 & 3 & 2 \\
\hline Total & 7 & 2 & 3 & 3 & 6 & 4 & 9 & 6 & 2 & 4 & 4 & 2 \\
\hline
\end{tabular}

Objective of this paper is to provide usability dimensions for evaluating usability for deaf people m-banking application usage; therefore four dimensions have been identified. The model have identified the use of three dimension having mentioned in highest number of literature and has been used constantly. The dimension is derived from ISO 9241-11 (1998) which consist of effectiveness, efficiency and satisfaction. However, m-banking for deaf are hardly been recognized in evaluation usefulness of the application for them. As such, this study will introduce the least used but important dimension for the deaf application usability evaluation which is the accessibility. The following section introduces the m-banking usability model for deaf and describes in detail each of the attributes of usability mentioned below.

\section{Discussion}

Through the SLR conducted, four dimension has been identified to be appropriate to suit the need of m-banking application usability evaluation especially for the deaf people. As such, the chosen dimension and measurements for each dimension has been described as below.

Efficiency: Ability of the user in completing their task with speed and accuracy (Abubakar, 2016). This attribute reflects the productivity of a user while using the application. Attributes under this dimension as such as:

- Compatibility: Any extent to which user interface is compatible with different mobile devices and deaf people capability.

- Loading time: This measure the time required for the application in loading in to mobile device.

Therefore, integrating the two measurements will determined the efficiency of $\mathrm{m}$ banking application interface.

Effectiveness: Effectiveness is the ability of a user in completing any task in a specified context (Harrison et al., 2013; ISO 9241-11, 1998). This is commonly measured by evaluating whether or not participants can complete a set of specified tasks. Attributes under this dimension as such as:

- Accuracy: this measures performance of application in completing specified task and within a time.

- Presentation: Refers to the logical presentation of the menu buttons (visibility of important option which can easily be understood by user), graphic, interface layout and the readability of the output. 
Satisfaction: Identifies the attitude of user towards using an application since if an application is satisfying, users will have more interest in using the applications frequently and continuously (Dubey et al., 2012; Martin \&Oruklu, 2012). Attributes under this dimension as such as:

- Content: Measures on the content addresses the user's objectives and whether the content has value to the user.

- Application guide: Measures the extent to which navigation is structured appropriately for easy to reach especially for the deaf in finding contents.

Therefore, there two measurements can be integrated to measure the user satisfaction for m-banking application interface. Besides these three dimensions, accessibility has been identified to suit the need of m-banking usability evaluation for the deaf people as their need for any application differs from normal people. As such, accessibility is described as below.

Accessibility: This dimension addresses the needs of the deaf directly. This measures the accessible level of an application by this community with minimal effort and in accordance with the requirements fulfilled (Nathan et al., 2018). Attributes under this dimension as such as:

- Operable: Understanding the application flow easily and able to complete task in lesser time. This will also measure the level of presentation as structured in the application and allow users to move around easily in the application.

- Assistive: Assistance provided to the deaf user in completing a task. Animation, multimedia and more content values should be included in the application for the hearing-impaired to ensure the application is able to be used easily.

Therefore, there two measurements can be integrated to measure the level of accessibility for the deaf user in using m-banking application interface. As such, these four main dimensions will be used in measuring the usability of the m-banking application among the deaf.

\section{$7 \quad$ Implications and Conclusion}

The emergence of M-banking usability evaluation has implications more broad arrangement of digital economy in developing countries. Every exchange is impacted by the basic position of individuals in more extensive educational systems. The most recent instance of M-keeping money frameworks is an update that a comprehension of the job of the portable in creating social orders must incorporate its job in intervening both social and monetary exchanges, some of the time all the while. In light of the fact that technologies as utilized by people who are deaf are additionally utilized by the all-inclusive community, there are more open doors for people who are deaf to make associations with a more extensive assortment of individuals.Informal communication locales, for example, Facebook, Twitter and Instagram could enable separate to social hindrances that regularly exist between people who are deaf and people who are hearing, maybe additionally bringing a common comprehension of one another's require- 
ments and societies. In addition, there are instructive ramifications for the hard of hearing network in these outcomes. Innovation can possibly improve and strengthen training among deaf.

Unequal access to data, technology and innovations are said to be impeded in the worldwide economy. Utilization of innovation and full access to programming projects and Web destinations emphatically influences academic success, advances professional careers, and connects persons socially. In future, we encourage legal, educational, and humanitarian professionals in deaf communities to work to make full and equivalent access to innovation and technology so that deaf people can take part completely and effectively in worldwide and overall contribute to economy growth as well. Finally, banking sector should keep pace with innovation that enables the deaf community to maintain equal opportunityand overall achieve the sustainable development.

\section{References}

[1] Akamatsu, C. T., Mayer, C., \&Farrelly, S. (2005). An investiga- tion of two-way text messaging use with deaf students at the secondary level. Journal of Deaf Studies and Deaf Education, 11(1), 120-131. https://doi.org/10.1093/deafed/enj013

[2] Abubakar, H.I. (2016). Usability Evaluation Model for Mobile Banking Applications Interface. (Unpublished doctoral dissertation). Universiti Utara Malaysia, Kedah Malaysia.

[3] Abubakar, H. I., Hashim, N. L., \& Hussain, A. (2016). Usability Evaluation Model for Mobile Banking Applications Interface: Model Evaluation Process using Experts' Panel. Journal of Telecommunication, Electronic and Computer Engineering (JTEC), 8(10), 5357.

[4] Baharuddin, R., Singh, D., \&Razali, R. (2013). Usability Dimensions for Mobile Applications-A Review. Research Journal of Applied Sciences, 5(6), 2225-2231. https://doi.org/ 10.19026/rjaset.5.4776

[5] Coursaris, C. K., \& Kim, D. J. (2011). A meta-analytical review of empirical mobile usability studies. Journal of Usability Studies, 6(3), 117-171.

[6] Dubey, S. K., Gulati, A., \& Rana, A. (2012b). Integrated Model for Software Usability. International Journal on Computer Science \& Engineering, 4(3). 429-437.

[7] Harkins, J., \& Bakke, M. (2003). Technologies for communication: Status and trends. In M. Marschark\& P. E. Spencer (Eds.), Oxford handbook of deaf studies, language and education (pp. 407-419). New York, NY: Oxford University Press. doi:10.1093/oxfordhb/ 9780199750986.013.0030. https://doi.org/10.1093/oxfordhb/9780199750986.001.0001

[8] Harrison, R., Flood, D., \& Duce, D. (2013). Usability of mobile applications: literature review and rationale for a new usability model. Journal of Interaction Science, 1(1), 1. https://doi.org/10.1186/2194-0827-1-1

[9] Hussain, A., Abubakar, H. I., \&Hashim, N. B. (2014, November). Evaluating mobile banking application: Usability dimensions and measurements. In Information Technology and Multimedia (ICIMU), 2014 International Conference on (pp. 136-140). IEEE. https://doi. org/10.1109/icimu.2014.7066618

[10] International Organization for Standardization (1998). International Standard: ISO 9241 11(Guidance on Usability). Geneva.

[11] Kitchenham, B. (2004). Procedures for performing systematic reviews. Keele, UK, Keele University, 33(2004), 1-26. 
[12] Low, Y.M., Goh, C.F., Kowang, O. \&Rasli, T.A. (2017). Users’ Loyalty Towards Mobile Banking In Malaysia, Journal Of Internet Banking And Commerce, 22 (7).

[13] Martin, C. G., \&Oruklu, E. (2012). Human friendly interface design for virtual fitting room applications on android based mobile devices. Journal of Signal and Information Processing, 3(04), 481. https://doi.org/10.4236/jsip.2012.34061

[14] Murat Mahad ,ShahimiMohtar, Abdul Aziz Othman. (2016). Examining The Influences Of Risk Towards Adoption Of Mobile Banking In Malaysia: An Extended Decomposed Theory Of Planned Behavior, Labuan e-Journal of Muamalat and Society, 10, pp. 1-15

[15] Nathan, S. S., Hussain, A., \&Hashim, N. L. (2016). Studies on Deaf Mobile Application: Need for Functionalities and Requirements. Journal of Telecommunication, Electronic and Computer Engineering (JTEC), 8(8), 47-50.

[16] Nathan, S. S., Hussain, A., \&Hashim, N. L. (2018). Usability Evaluation of DEAF Mobile Application Interface: A Systematic Review. Journal of Engineering and Applied Sciences, 13(2), 291-297.

[17] Nathan, S. S., Berahim, M, Ramle, R, Hussain, A., Hashim, N. L, Ain, A. Q. (2018). Accessibility, Disability and Deaf: a Review. International Journal of Engineering and Technology, (19), 369-373.

[18] Ow,S.H., SalimahMokhtar\&RoziatiZainuddin. (2007). A Review on the Teaching and Learning Resources for the Deaf Community in Malaysia, Chiang Mai Journal.

[19] Power, M. R., \& Power, D. (2004). Everyone here speaks txt: Deaf people using SMS in Australia and the rest of the world, Journal of Deaf Studies and Deaf Education, 9, 333343. https://doi.org/10.1093/deafed/enh042

[20] Rowland, C., Burgsthaler, S., Smith, J., \& Coombs, N. (2013). Issues in accessing distance education technologies for individuals with disabilities. Retrieved from http://ncdae.org/ resources/articles/technology.php

[21] Sangar, A. B., \&Rastari, S. (2015). A model for increasing usability of mobile banking apps on smart phones. Indian Journal of Science and Technology, 8(30). https://doi.org/10. $17485 / \mathrm{ijst} / 2015 / \mathrm{v} 8 \mathrm{i} 30 / 85690$

[22] Sey, A., Coward, C., Bar, F., Sciadas, G., Rothschild, C., \&Koepke, L. (2013). Connecting people for development: Why public access ICTs matter. Seattle: Technology \& Social Change Group, University of Washington Information School.

[23] Yeratziotis, A., \&Zaphiris, P. (2018). A Heuristic Evaluation for Deaf Web User Experience (HE4DWUX). International Journal of Human-Computer Interaction, 34(3), 195217. https://doi.org/10.1080/10447318.2017.1339940

[24] Zhuo, Q., \& Li, Y. (2010). Chinese Mobile Banking Service Evaluation Based on AHP Method. Paper presented at the International Conference on E-Product, E-Service and EEntertainment (ICEEE). https://doi.org/10.1109/iceee.2010.5661025

\section{Authors}

Shelena Soosay Nathan is the senior lecturer at Department of Information Technology at Center for Diploma Studies, UniversitiTun Hussein Onn Malaysia, Johor Malaysia. She obtained her PhD in Usability domain in Information Technology on 2018. Most of the research studies related to usability and deaf people mobile application. She is also a member of Malaysian Board of Technologist (MBOT) and actively involved publishing journal articles in related field. shelena@uthm.edu.my 
Vikniswari Vija Kumaran is an assistant professor in Department of Economics, UniversitiTunku Abdul Rahman (UTAR), Malaysia. She obtained her PhD degree in Industrial sector Analysis- Efficiency, Productivity and Profitability in 2016. Most of her publications were related to efficiency and profitability. She has become the reviewer for internal research grant, conference papers and journal articles. She has delivered talk related to medical tourism for students from GUIZHOU University, China. Currently, she is interested in renewable energy consumption and the efficiency of renewable energy sector. She has attended national and international conferences and published her works in the field of efficiency and energy.

Azham Hussain is the Associate Professor of Software Engineering at School of Computing, Universiti Utara Malaysia, Kedah, Malaysia. He is the founder of Human-Centered Computing Research Group, which is affiliated with the Software Technology Research Platform Center at School of Computing, Universiti Utara Malaysia. Azham Hussain is a member of the US-based Institute of Electrical and Electronic Engineers (IEEE), and actively involved in both IEEE Communications and IEEE Computer societies. azham.h@uum.edu.my

Nor Laily Hashim is currently supervising several $\mathrm{PhD}$ students in the area of software architecture, software testing, self-adaptive and mobile usability evaluation. She also teaching master courses related to software development and programming. Her research work involves areas in software testing, mobile usability, impact of social media in business, and STEM education in Malaysia. laily@uum.edu.my

Article submitted 2019-08-13. Resubmitted 2019-10-23. Final acceptance 2019-10-23. Final version published as submitted by the authors. 